\title{
Obesity and risk of pneumonia in patients with influenza
}

\section{To the Editors:}

In a recent issue of the European Respiratory Journal, KORNUM et al. [1] demonstrated a strong association between obesity and increased risk of subsequent hospitalisation with pneumonia in a prospective cohort of 48,551 subjects in Denmark. Nevertheless, adjustment for major chronic diseases eliminated the association between obesity and pneumonia risk. Interestingly, although obesity was related to increased pneumonia risk in patients with pandemic influenza A (H1N1) infection in 2009 [2] it remains unclear whether higher risk of increased disease severity can be explained by the occurrence of other chronic diseases in such patients. Therefore, we analysed the role of obesity in the development of pneumonia in a cohort of 158 patients hospitalised with H1N1 infection in 2009 at the tertiary referral centre. Pneumonia was diagnosed in 80 patients based on clinical presentation (acute cough, dyspnoea, tachypnoea and fever) and the presence of a new infiltrate on chest radiography. In 65 of these patients, pneumonia was diagnosed at the time of hospital admission and in the remaining 15 cases pneumonia developed within the median of 1 day of hospital stay (25th-75th percentile: 1-3 days). In patients with pneumonia, mean leukocyte count at admission was (median, 25th-75th percentile) 5.65 (4.03-8.59) $\mu \mathrm{L}^{-1}$; leukocyte counts $<10,000 \mu \mathrm{L}^{-1}$ were present in $66(83 \%)$ patients and leukopoenia $<4,000 \mu \mathrm{L}^{-1}$ in $21(26 \%)$ patients. The interstitial or mixed radiological pattern was present in 56 (70\%) subjects, pleural effusion did not occur in any patient. Such findings are consistent with H1N1 pneumonia as recently described by RiQuelme et al. [3]. Compared with patients without pneumonia, those with this complication were older and had higher body mass index (BMI) (mean \pm SD: $39.9 \pm 18.1$ versus $46.9 \pm$ $14.4 \mathrm{yrs}, \mathrm{p}=0.008$; and $24.3 \pm 5.1$ versus $29.3 \pm 6.7 \mathrm{~kg} \cdot \mathrm{m}^{-2}$, $\mathrm{p}<0.001$, respectively). No differences were observed in the proportion of females or in the Charlson score between the two groups ( $45 \%$ versus $56 \%, \mathrm{p}=0.204 ; 0.46 \pm 0.86$ versus $0.56 \pm 0.87$, $\mathrm{p}=0.465$, respectively). In multiple logistic regression analysis, BMI was related to higher odds for pneumonia (OR 1.15, 95\% CI $1.07-1.23 ; \mathrm{p}<0.001$ ) and the use of oxygen therapy (OR 1.11,95\% CI 1.04-1.18; $\mathrm{p}=0.002)$, independently of age, sex and Charlson index. Subgroup analyses by sex yielded similar results (data not shown). Our study, albeit in a small number of patients, is one of the few reports where obesity has been found to be an independent risk factor for influenza severity [4].

Increased risk for severe H1N1 infection in obese subjects may be related to complications of obesity during intensive care; with a severe course of the disease due to diabetes, or with interference of obesity with the host's immune responses. The latter possibility has been examined in several studies in rodents. SMITH et al. [5] have demonstrated that diet-induced obese mice were more susceptible to morbidity and mortality during influenza infection than lean mice, namely due to altered innate immune responses characterised by minimal induction of interferon- $\alpha / \beta$, delayed expression of pro-inflammatory cytokines and chemokines, impaired natural killer cytotoxicity and impaired dendritic cell presentation. Thus, the function of influenza-specific memory T-cells is significantly reduced and ineffective in obese mice. In contrast to animal studies, the potential role of obesity in immune dysregulation during influenza infection has not been addressed in humans directly. Nevertheless, the reality of a worldwide obesity epidemic combined with yearly influenza outbreaks suggests the need to understand in depth how influenza virus may affect immune responses in obese individuals.

\section{Schreter*, P. Kristian* and R. Tkacova"}

*Depts of Infectology and Travel Medicine, and "Respiratory Medicine and Tuberculosis, Faculty of Medicine and L. Pasteur Teaching Hospital, P.J. Safarik University, Kosice, Slovakia.

Correspondence: R. Tkacova, Dept of Respiratory Medicine, Medical Faculty, P.J. Safarik University, Rastislavova 43, 04190 Kosice, Slovakia. E-mail: ruzena.tkacova@upjs.sk

\section{SUPPORT STATEMENT}

This study was supported by the Project "Centre for Excellent Research of Atherosclerosis", Operational Programme Research and Development funded by the European Regional Development Fund.

Statement of Interest: None declared.

\section{REFERENCES}

1 Kornum JB, Nørgaard M, Dethlefsen C, et al. Obesity and risk of subsequent hospitalisation with pneumonia. Eur Respir J 2010; 36: 1330-1336.

2 Vaillant L, La Ruche G, Tarantola A, et al. Epidemiology of fatal cases associated with pandemic H1N1 influenza 2009. Euro Surveill 2009; 14: 19309.

3 Riquelme R, Torres A, Rioseco ML, et al. Influenza pneumonia: a comparison between seasonal influenza virus and H1N1 pandemic. Eur Respir J 2010; [Epub ahead of print DOI: 10.1183/09031936.00125910].

4 Santa-Olalla Peralta P, Cortes-Garcia M, Vicente-Herrero M, et al. Risk factors for disease severity among hospitalised patients with 2009 pandemic influenza A (H1N1) in Spain, April-December 2009. Euro Surveill 2010; 15: 19667.

5 Smith AG, Sheridan PA, Tseng RJ, et al. Selective impairment in dendritic cell function and altered antigen-specific CD8+ T-cell responses in diet-induced obese mice infected with influenza virus. Immunology 2009; 126: 268-279. 